\title{
REVERSIBLE ENANTIOSELECTIVITY OF ENZYMATIC REACTIONS
} BY MEDIA

\author{
Shih-Hsiung $\mathrm{Wu}^{{ }^{* 1}}, \mathrm{Fei-Ya} \mathrm{Chu}^{2}$ and Kung-Tsung Wang ${ }^{1,2}$ \\ 'Institute of Biólogical Chemistry; Academia sinica, \\ ${ }^{2}$ Department of Chemistry, National Taiwan University, \\ Taipei, Taiwan, ROC
}

(Received 14 May 1991)

Summary : The esterification of racemic 2-(4-chlorophenoxy) propionic acid and n-butanol by the lipase from candida cylindracea in different reaction media showed reverse enantioselectivity, pro-R enantiomer in n-hexane, isooctane, cyclohexane, toluene and aqueous phase; and pro-s in dichloromethane, acetone, n-butanol and tetrahydrofuran.

Because of its relatively high stability in organic media, the lipase from candida cylindracea has been widely used as catalysts for the preparation of chiral compounds in organic solvent ${ }^{1-6}$. According to the previous reports, the lipase was a glycoprotein with high content of hyarophobic amino acids ${ }^{7}$. Recently, commercial crude powder of the lipase have been shown very high purity without contamination of any esterase and its molecular weight was about $60,000^{8}$. In this communication, we reported that the esterification of 2-(4-chlorophenoxy) propionic acid and $n$-butanol by the lipase in different reaction media showed reversible enantioselectivity.

As the results shown in Table $1 .$, the enantioselectivity of the lipase toward racemic 2-(4-chlorophenoxy) propionic acid was quite low and showed slightly pro-R enantioselectivity in apolar solvents such as n-hexane, isooctane, cyclohexane and toluene in esterification reaction with $n$-butanol. However, if the reaction proceeded in phosphate buffer or apolar solvents containing $2 \%$ (by volume) of water, the enantioselectivity increased significantly and still kept pro-R oriented property. Surprisingly, the pro-R enantioselectivity could be reversed to pro-s, if the reaction proceeded in medium polar solvents such as dichloromethane, acetone, n-butanol and tetrahydrofuran (THF). 
No esterification can be observed in dimethylformamide or acetonitrile. This phenomenon strongly indicated that the active site of the lipase can be altered by organic solvents to reverse enantioselectivity.

With no contamination by other esterase in the crude powder of the lipase, the results raised from enzymes other than the lipase have been ruled out ${ }^{8}$. Despite many advantages of enzymatic reactions in organic solvents, stereoselectivity, which is a hallmark of enzymatic catalysis, may dramatically reduce ${ }^{9-11}$. On the basis of protein chemistry, the hydrophobic amino acid residues of protein molecules are usually buried in the interior of the molecules and the hydrophilic residues are exposed on the surface to contact with aqueous solution ${ }^{12}$. Furthermore, it has been mentioned that the active site of an enzyme is situated in a limited region of the protein which is more flexible than the molecule as a whole ${ }^{13}$. Therefore, the inside hydrophobic residues tend to disperse and alter the conformation of molecules, if aqueous solution is replaced by organic media. The perturbed molecules, if still active, then have broader specificity of substrates which may lead to lose or reduce enantioselectivity ${ }^{14}$. Because of the hydrophobic property of natural substrates, the active site of the lipase are envisioned as hydrophobic pockets. Therefore, it is then reasonable to explain the lower enantioselectivity of the lipase in apolar solvents by hydrophobic interaction. However, how the moderate or high polar solvents interact with the lipase to reverse enantioselectivity remains unclear. In general, the catalytic efficiency of enzymes decreases as the polarity of the solvent increases and it is believed that hydrophilic solvents may alter or denature enzymes by stripping off the essential water from enzymes, then penetrate into the hydrophobic core of proteins to interfere their delicate structures $^{15}$. Compared with hydrophobic solvents, the interference on protein structures by hydrophilic solvents is more complicated.

Several examples have been described about changing the selectivity of enzymes by reaction solution ${ }^{16-18}$. Nevertheless, our finding first shows that the enantioselectivity of the enzyme can be reversed by reaction media. 
Table 1. Enantioselectivity of Lipase of in the esterification of 2-(4-chlorophenoxy) propionic acid and n-butanol in different media

\begin{tabular}{|c|c|c|c|c|c|}
\hline $\begin{array}{l}\text { reac } \\
\text { time }\end{array}$ & $\begin{array}{l}\text { tion } \\
(\mathrm{h})\end{array}$ & ees & $e_{p}$ & $\begin{array}{c}\text { Conversion } \\
\text { (z) }\end{array}$ & $E^{b}=-\frac{\left(k_{\text {cat }} / K_{m}\right)_{R}}{\left(k_{\text {cat }} / k_{m}\right)_{s}}$ \\
\hline isooctane & 4 & 0.05 & 0.13 & 29 & 1.4 \\
\hline cyclohexane & 4 & 0.02 & 0.17 & 10 & 1.4 \\
\hline n-hexane & 4 & 0.01 & 0.03 & 25 & 1.1 \\
\hline toluene & 4 & 0.01 & 0.09 & 10 & 1.2 \\
\hline $\mathrm{CH}_{2} \mathrm{Cl}_{2}$ & 4 & 0.67 & 0.36 & 65 & 0.25 \\
\hline ethyl acetate & 24 & 0.39 & 0.37 & 51 & 0.32 \\
\hline n-butanolc & 24 & 0.45 & 0.28 & 62 & 0.38 \\
\hline THF & 18 & 0.03 & 0.59 & 4 & 0.25 \\
\hline acetone & 24 & 0.01 & 0.61 & 1 & 0.24 \\
\hline buffer & 27 & 0.33 & 0.89 & 27 & 24 \\
\hline $\begin{array}{l}\text { n-hexane } \\
(2 \% \text { buffer })^{\circ}\end{array}$ & 72 & 0.51 & 0.86 & 38 & 21 \\
\hline
\end{tabular}

- The acid ( $1 \mathrm{mmol}, 200 \mathrm{mg}$ ) and n-butanol (1 mmol, $75 \mathrm{mg}$ ) were mixed in $1.5 \mathrm{ml}$ of the desired medium, to which $200 \mathrm{mg}$ of lipase of (Candida cylindracea, Meito-sangyo Ltd., Japan) was added. After checked by TLC to make sure the formation of the ester, the reaction was terminated by filtering the organic medium to remove the enzyme. The organic extract was dried over $\mathrm{Na}_{2} \mathrm{SO}_{4}$, and evaporated to dryness under reduced pressure. The residue was chromatographed over a silica gel column by eluting with hexane-ethyl acetate $(7: 1$ and $2: 1$ ) for the ester and the remaining acid, respectively. The remaining acid was converted into methyl ester by the treatment of diazomethane in ether solution and its enantiomeric excess (ees) can be determined by HPLC on a chiral-2 column (Macherey-Nagel, Düren, W. Germany) with n-heptane containing $0.05 \%$ isopropanol and $0.05 \%$ trifluoroacetic acid as eluent (flow rate: 1 $\mathrm{ml} / \mathrm{min}$; detector : UV $254 \mathrm{~nm})$. The retention time of two enantiomers are $10.0 \mathrm{~min}$ for R-methyl ester and $11.4 \mathrm{~min}$ for $s$-methyl ester. The ee of $n$-butyl ester product can also be analyzed directly by HPLC with the same conditions described above. The retention times of $R$-and $S$-butyl esters are $8.6 \mathrm{~min}$ and $9.8 \mathrm{~min}$, respectively. The $\mathrm{E}$ value was calculated on the basis of no reverse reaction.

- E value was defined and calculated according to the report of chen et $\mathrm{al}^{19}$. Conversion is the yield of the ester and ee and ee are the enantiomeric excess of remaining substrate (acid) and product (ester).

c n-Butanol was used as media and alcohol substrate in this reaction.

d The esterification was carried out in phosphate buffer $(0.2 \mathrm{M}$, $\mathrm{pH} 7.0$ ) solution.

- The reaction proceeded in $n$-hexane containing 28 phosphate buffer $(0.2 \mathrm{M}$, pH 7.0). 
References :

1. C. S. Chen, S. H. Wu, G. Girdaukas and C. J. Sih, J. Am. Chem. Soc. 109 (1987) 2812 .

2. B. Cambou, and A. M. Klibanov, J.Am. Chem. SoC. 106 (1984) 2687 .

3. G. Langrand, M. P. Secchi, G. Buono, J. Baratti and C. Triantaphylides, Tet. Lett. 26 (1985) 1857.

4. Y. F. Wang, J. J. Lalonde, M. Momongan, D. E. Bergbreiter, and C. H. Wong, J.Am. Chem. Soc, 110 (1988) 7200 .

5. C. S. Chen and C. J. Sih, Angew. Chem. Int. Ed. Engl. 28 (1989) 695 .

6. G. Kirchner, M. P. Scollar and A. M. Klibanov, J. Am. Chem. Soc. 107 (1985) 7072 .

7. N. Tomizuka, Y. Ota and K. Yamada, Agr. Biol. Chem. 30 (1966) 576 and 1096.

8. (a) S. H. Wu, Z. W. Guo and C. J. Sih, J. Am. Chem. Soc, 112 (1990) 1990.' (b) P. Y. Chen, Master Thesis (1991), Institute of Biochemical Sciences, National Taiwan University.

9. C. H. Wong, science, 244 (1989) 1145.

10. T. Sakurai, A. I. Margolin, A. J. Russell and A. M. Klibanov I. Am. Chem. SoC. 110 (1988) 7236 .

11. H. Kitaguchi, P. A. Fitzpatrick, J. E. Huber and A. M. Klibanov, J.Am. Chem. Soc. 111 (1989) 3094.

12. A. A. Klyosov, N. Van Veit and I. V. Berezin, Eur. J. Biochem. 59 (1975) 3 .

13. C. L. Tsou, Trends Biochem. Sci. 11 (1986) 427.

14. A. M. Klibanov, Trends Biochem. Sci. 14 (1989) 141.

15. A. Zaks and A. M. Klibanov, J. Biol. Chem. 263 (1988) 3194 .

16. A. Zaks and A. M. K1ibanov, I. Am. Chem. Soc. 108 (1986) 2767.

17. C. F. Barbas III, J. R. Matos, J. B. West, and C. H. Wong, J. Am. Chem. Soc. 110 (1988) 5162 .

18. Z. W. Guo, and C. J. Sih, J.Am. Chem. Soc. 111 (1989) 6836 .

19. C. S. Chen, Y. Fujumoto, G. Girkaudas, and C. J. Sih, J. Am. Chem. Soc. 104 (1982) 7294 . 